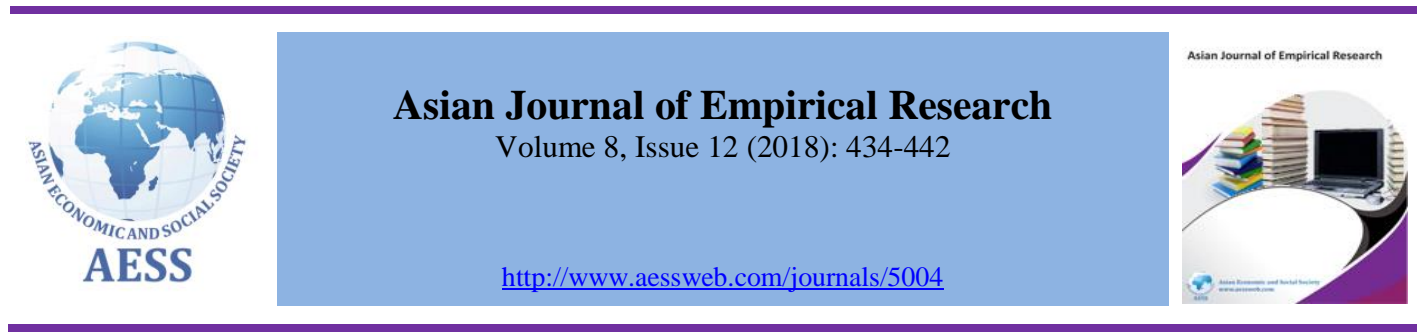

\title{
Mediation using covariance based-structural equation modeling (CB-SEM): the why and how?
}

\author{
Mohammad Mizanur Rahman ${ }^{a}$, Samuel Babatunji Adedeji ${ }^{\mathrm{a}}$ Md Abdul Bashir ${ }^{\mathrm{a}}$, Jahirul \\ Islam $^{b}$, Md Reaz ${ }^{c}$, Arif Md. Khan ${ }^{\text {d }}$ \\ a PhD Student; Faculty of Economics and Management, Universiti Putra Malaysia, Malaysia \\ ${ }^{\mathrm{b}} \mathrm{PhD}$ Student; Faculty of Modern Languages and Communication, Universiti Putra Malaysia, \\ Malaysia \\ ${ }^{\mathrm{c}} \mathrm{PhD}$ Student; School of Business, Western Sydney University, Australia \\ ${ }^{\mathrm{d}}$ Masters Student; Faculty of Economics and Management, Universiti Putra Malaysia, Malaysia \\ \. mrahman@metrouni.edu.bd Corresponding author
}

\section{ARTICLE HISTORY:}

Received: 28 -Oct-2018

Accepted: 14-Dec-2018

Online available: 31 -Dec-

2018

\section{Keywords:}

Baron and Kenny, Covariance,

Mediation analysis,

Preacher and Hayes, and

structural Equation modeling

ABSTRA C T
This paper summaries and provides answers to some of the
challenging issues in relation to mediation analysis. Specifically,
emphasis was on four key burning aspects with reference to up-to-
date literature on mediation analysis. For a better appreciation of the
efforts put in here, scholars and practitioners, have some guidelines
suggested to conceptualise, test and interpret a simple mediation
model. Researchers have the benefits of updating their knowledge
base from the current citations provided to carry out proper analysis
based on informed decisions.

ABSTRACT

This paper summaries and provides answers to some of the challenging issues in relation to mediation analysis. Specifically, emphasis was on four key burning aspects with reference to up-todate literature on mediation analysis. For a better appreciation of the efforts put in here, scholars and practitioners, have some guidelines suggested to conceptualise, test and interpret a simple mediation model. Researchers have the benefits of updating their knowledge based on informed decisions.

\section{Contribution/ Originality}

This study has created awareness in relation to the drawbacks and applications of the CB-SEM as a statistical technique for mediation analysis in the behavioural and social sciences and its relevance in the future. Apart from the justification as a method for research analysis, the study derives its relevance from the need to address the challenges faced by researchers in the application of the technique and the required ways out of them.

DOI: 10.18488/journal.1007/2018.8.12/1007.12.434.442

ISSN (P): 2306-983X, ISSN (E): 2224-4425

How to cite: Mohammad Mizanur Rahman, Samuel Babatunji Adedeji, Md Abdul Bashir, Jahirul Islam, Md Reaz and Arif Md. Khan (2018). Mediation using covariance based-structural equation modeling (CB-SEM): the why and how? Asian Journal of Empirical Research, 8(12), 434-442

(C) 2018 Asian Economic and Social Society. All rights reserved 


\section{INTRODUCTION}

The mechanism for ascertaining the efficacy of theories for comprehending the cause-effect association between variables is mediation (Baron and Kenny, 1986; Preacher and Hayes, 2004). Furthermore, the latter is fundamental, to fostering research efforts in accounting, finance, economics, management, and humanities especially with respect to advancing the body of knowledge. Also, it is the basis for the development of theories and enhancement of appreciation for the essence of intervening variables in explaining the interrelations among independent and dependent constructs (Wood et al., 2008; Pieters, 2017). Consequently, the issues relating to mediation are beginning to gain acceptance and prominence with researchers in the developed and developing economies, as well as those in the emerging nations. However, present-day studies are for the advancement of literature globally in other disciplines such as clinical studies, marketing and consumer behaviour, supply chain management, strategic research and educational studies (Green et al., 2010; Hayes and Rockwood, 2016; Pieters, 2017; Rungtusanatham et al., 2014; Aguinis et al., 2017; Fairchild and McQuillin, 2010) for academic research reasons.

Even though, there are evidences all over the globe to support the literature in relation to the application of mediation in the current research efforts, however, it is disheartening to see that many areas of concern still exist (Green et al., 2016; Hayes, 2013; Aguinis et al., 2017). The identified concerns are inclusive of the non-relenting efforts by many researchers at adhering to the causal processes that Baron and Kenny (1986) advocated. Also, is adoption of old techniques by researchers for their studies (Aguinis et al., 2017; Rucker et al., 2011). Again, is the pictorial and written representations of the mediation effects not supported with the required hypotheses (Rungtusanatham et al. 2014). Furthermore, is the continued lack of justification for the mediation effect in particular (Aguinis et al., 2017; Miller et al. (2007).

Nevertheless, the purpose of this study is to project the knowledge and understanding with respect to mediation analysis in order increase the level of appreciation of researchers (instructors, practitioners and especially post graduate scholars and fellows) for it in not only the advanced economies, but, also in the emerging and developing nations. Subsequently, efforts made here are to take advantage of current literature to address the areas of concern in order to come up with suggestions that can make for easy conceptualisation, testing, interpretations and reporting of the mediation models. In sum, the beauty of this study is to convey the hands-on steps that can ensure that researchers are able to achieve their aim with ease by adopting the mediation process.

\section{CB-SEM AT A GLANCE}

The fundamental objective of CB-SEM is to evaluate the good fit between the observed covariance matrix and the theoretical covariance matrix. In other words, it is for determining the extent to which a suggested theoretical model validates the authenticity of the framework considered. However, for the purpose of application, CB-SEM is of relevance when the research is confirmatory in nature and theory testing or the evaluation of alternative theories constitute the reason for the study (Hair et al., 2017b). Furthermore, it is useful whenever only reflective models are involved. Hence, CB-SEM is in relation to models with loops of relationships between latent constructs (Hair et al., 2017b; Hair et al., 2011). Other points that are of significance in relation to CB-SEM are that the researcher must ensure that the data for the analysis have passed the multivariate normality test, aside from the usage of the maximum likelihood estimation method. Most postgraduate students and their supervisors in Malaysia are guilty of underscoring the need for observing the distributional assumptions when the CB-SEM is for the purpose of analysis (Memon et al., 2017). 


\section{BASIC CONCEPTS OF MEDIATION ANALYSIS}

The relationship between a causal agent $\mathrm{X}$ and a subsequent $\mathrm{Y}$ variable has an answer in a statistical method referred to as mediation analysis. The fundamental mediation model, (i.e. the simple mediation model) is in the conceptual diagram in Figure 1 below. The latter depicts two resultant variables $(M)$ and $(Y)$ and two predecessor variables $(X)$ and $(M)$, with $Y$ and $M$ causally influenced by $X$, and $M$ on $Y$. Therefore, where one causal antecedent $X$ variable influences an outcome $Y$ via a single intervening variable $M$, a simple mediation model exists with two separate pathways, by which a specific $X$ variable influences a $Y$ variable. Firstly, the pathway that runs through from $X$ to $Y$ without connecting $M$ is the direct effect of $X$ on $Y$. Secondly, the pathway that is from $X$ to $Y$ is the indirect effect of $X$ on $Y$ through $M$. The movement is then from precedent $X$ to subsequent $M$ and then from precedent $M$ to consequent $Y$. Thus, the pictorial representation shows the indirect effect of $X$ on $Y$ through a connecting structure, in which $X$ influences $M$, and the latter in turn influences $Y$.

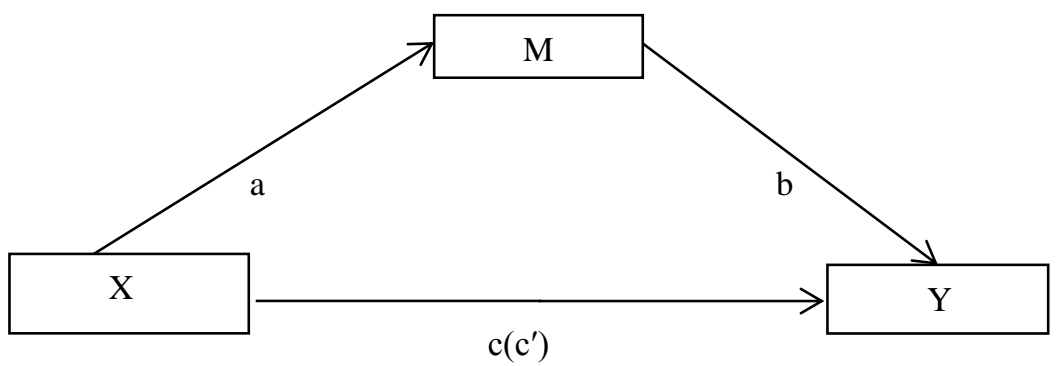

Figure 1: Simple mediation model

In a mediational model, $M$ is typically called a mediator variable, although the term intermediary variable has been used, and different fields use different terms, such as a surrogate variable or an intermediate endpoint. The term mediator is preferred in this study because it is probably the most widely used and recognized term. The mediation hypotheses are determinable by more statistically rigorous methods. According to Baron and Kenny (1986), the mediator variable ensures a more direct test of an indirect effect premised on a procedure developed by Sobel (1982) that is later reference as the Sobel test. However, in relation to simple mediation, the latter test helps to make a comparison of the strength of the indirect effect of $\mathrm{X}$ on $\mathrm{Y}$ to the point that null hypothesis $=0$. The product of the $\mathrm{X}$ $\rightarrow \mathrm{M}$ path (a) and the $\mathrm{M} \rightarrow \mathrm{Y}$ path (b), or ab is the indirect effect of $\mathrm{X}$ on $\mathrm{Y}$ under this circumstance. Commonly, $\mathrm{ab}\left(\mathrm{c} \mathrm{c}^{\prime}\right)$, denotes where $\mathrm{c}$ is the simple (total) effect of $\mathrm{X}$ on $\mathrm{Y}$, without controlling for $\mathrm{M}$, and $\mathrm{c}^{\prime}$ is the $\mathrm{X} \rightarrow \mathrm{Y}$ as the path coefficient after the inclusion of $\mathrm{M}$ to the model.

\subsection{Practical example of simple mediation model}

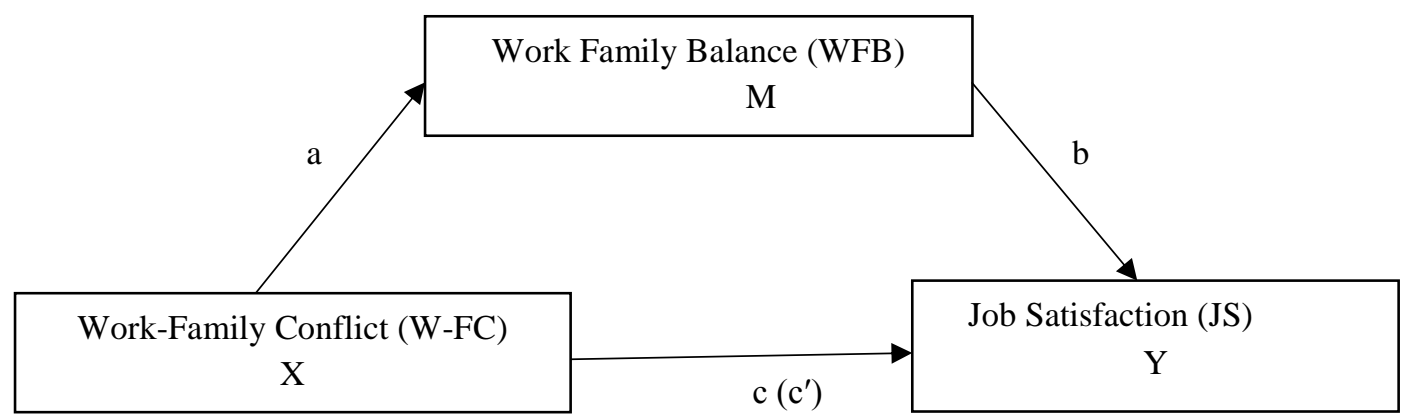

Figure 2: Simple mediation model (Practice Example) 
In the example used thus far, work family balance conceptualized as potential mediators of the effect of W-FC on JS. Once $W-F C$ exerts its effect on WFB, then the causal influence of WFB on $J S$ produces variation in $J S$. Historically, questions of "how" have been thought of as sensible to ask only after one has first established evidence of association between $W-F C$ and $J S$. As a result, mediation analysis would be undertaken only when one has successfully demonstrated that $W-F C$ and $J S$ are associated. This rationale is based on one of the three popular criteria one must meet to establish cause: correlation between $W-F C$ and $J S$ (the other two criteria being establishing that work family precedes job satisfaction, and ruling out competing explanations).

\section{APPLICATION OF MEDIATION MODEL}

The simple mediation model is the fundamental model one can estimate, and without any doubt, it has significantly generalises the complex underlying forces through which $X$ influences $Y$ in actual processes that are researched into by scholars. Nevertheless, a thorough appreciation of this model is essential with respect to the applications. A simple mediation model is regularly estimated and constituents interpreted in the empirical social psychological (e.g., Alter and Balcetis, 2011; Righetti and Finkenauer, 2011). Cognitive (e.g., Debeer et al., 2009), clinical (Costa and Pinto-Gouveia, 2011; Gaudiano et al., 2010), health (e.g., Leonard and Rasmussen, 2011; Ruby et al., 2011), political (e.g., Duncan and Stewart, 2007; Wohl and Branscombe, 2009). The others are medical (e.g., Meade et al., 2011; Wagner et al., 2010), educational (e.g., Hughes and Coplan, 2010), communication (e.g., Goodall and Slater, 2010; Shrum et al., 2011), and business literatures (e.g., Brown and Baer, 2011; Patrick and Hagtvedt, 2011), among many other disciplines.

\section{CHALLENGES AND SUGGESTIONS}

\subsection{Pre-requirements for mediation analysis}

This constitute one of the basic questions that everyone need consider before embarking on a mediation analysis. The usage of multiple mediators to make for the complexity of a model and factoring in a mediator to determine its workability are neither a good counsel nor practice. Again, emphasising exclusively on statistical issues and data analysis tools would also not be sufficient to rationalise a mediation study. Nevertheless, the relevance of a mediation model is premised on the design decisions that should be given consideration precedent to any analysis and even before a study is embarked upon by a scholar or practitioner (MacKinnon et al., 2012). A common statement that $M$ will mediate the relationship between $X$ and $Y$ neither validates the role of mediator nor adds to the advancement of theory building. Therefore, there should be precedent explicit statement and justification concerning the need for a mediator in a model which require responses to two key questions: 1) why a mediator is desired and 2) which variable should be considered as the mediator, and why? Consequently, having a hindsight about the association between the variables of interest and the theoretical meaning behind them before the conceptualisation of a mediation relationship is of high importance (MacKinnon et al., 2012). Also, is the need to hypothesise explicitly for mediation effects 'to properly get involved in a theorizing exercise with a view to formulating the required hypotheses about the mediation effect before conducting a test and draw conclusion in relation to it' (Rungtusanatham et al., 2014). Among other issues, reliability and validity of the instrument, sample size to detect required effects, selection of appropriate software application and basic understanding of available approaches for mediation testing including their strengths and weakness are the key elements to be familiar with and understood before a conducting mediation analysis. Furthermore, a look at the work of MacKinnon et al. (2012) on the issues before, during and after mediation analysis will be of great value to researchers. Moreover, the review of ground breaking work on mediation by Baron and Kenny (1986) and James and Brett (1984), Preacher and Hayes (2004, 2008), Hayes (2009) and current masterworks by Aguinis et al. (2017), Rungtusanatham et al. (2014), and Schoemann et al. (2017) can be resourceful in understanding the fundamentals of mediation effects and their functionality. Also, recommended are the works of Aguinis et al. (2017), and Green et al. (2016) as 
well as the recent additions from Memon et al. (2017) which can serve as the premise for appreciating the general methodological issues and probable therapies for mediation analysis.

\subsection{Test for relationships among the variables}

According to Baron and Kenny (1986), the first condition for mediation analysis is the test of the relationship between $X$ and $Y$. However, such condition and step have made for the rejection of many mediating relationships and their untimely unpopularity (Hayes, 2009). Meanwhile, the basic principle of parsimony violated through the unpopular idea of testing for direct effects, which have eventually stimulated the investigation of models that are not in agreement with theory by researchers (Aguinis et al., 2017). Thus, a relationship between $X$ and $Y$ may not be of relevance in a mediation analysis (Hayes, 2009; MacKinnon et al., 2000; Preacher and Hayes, 2004; Rucker et al., 2011; Rungtusanatham et al., 2014; Shrout and Bolger, 2002; Zhao et al., 2010). Hence, the relationship between $X$ and $Y$ 'needs not be factored in when evaluating the mediating effect of $M$ on the effect of $X$ on $Y$ due to the irrelevance of the path in the mediated effect' (Aguinis et al., 2017). On the other hand, testing for the importance of $X \rightarrow Y$ before or after determining a mediation effect is old fashioned and unnecessarily preventive in nature. Consequently, the significance of the relationship between $X$ and $Y$ if suggested by theory due to the presence of mediation, should be investigated by researchers despite the latter. The testing of the direct relationship between $X$ and $Y$ need not be jettison by the researchers. Nevertheless, the formulation and standardisation of theory may endanger determination of $X \rightarrow Y$ for the benefit instituting a mere mediation effect. Therefore, in order to be able to overcome this sort of challenge in future studies, the contributions of the following authors can further be read for better understanding of the 'how' Aguinis et al. (2017), Rungtusanatham et al. (2014), Rucker et al. (2011), Zhao et al. (2010), Hayes (2009) and Memon et al. (2018).

\subsection{Number of formulated hypotheses}

The above is a questionable area about mediation. However, Rungtusanatham et al. (2014), have developed, articulated and recommended two major approaches in relation to clarifying the concern about how formulated hypotheses are for the mediation effects, which are segmentation and transmittal approaches. The segmentation approach, requires the formulation of three hypotheses: $\mathrm{H}_{1}$ ) independent variable $(X)$ effects mediator $(M), \mathrm{H}_{2}$ ) mediator $(M)$ effects outcome variable $(Y)$ and $\left.\mathrm{H}_{3}\right)$ mediation effect (e.g., $M$ mediates the relationship between $X$ and $Y$ ). This proposal has been supported by Zhou et al. (2011), Paulraj (2011) and Wu et al. (2010). In the case of the transmittal approach, the requirement is a single hypothesis, which states that the mediator $(M)$ mediates the relationship between $X$ and $Y$ with no focus on those hypotheses relating $X$ to $M$ and $M$ to $Y$, as summarized in Table 1 below based on our practice example (Figure 2). This latter suggestion is recognised by Rungtusanatham (2001) and Sarkis et al. (2010). However, for future reading and understanding with respect to formulating mediational hypotheses, practitioners, scholars and post graduate students can have their knowledge base enhanced by a further appreciation of the works of Rungtusanatham et al. (2014), Rahman et al. (2018) and Memon et al., (2018).

\section{Table 1: Summary of formulated hypotheses}

\begin{tabular}{ll}
\hline No & \multicolumn{1}{c}{ Formulated hypotheses } \\
\hline $\mathrm{H}_{1}$ & W-FC has significant effect on WFB \\
$\mathrm{H}_{2}$ & WFB has significant effect on JS \\
$\mathrm{H}_{3}$ & WFB mediates the relationship between W-FC and JS \\
\hline
\end{tabular}

\subsection{Testing the nature of mediation}

Hayes (2013), Hayes and Rockwood (2017) and Rucker et al. (2011) have based on the current review of literature on mediation opine that partial and full mediation concepts are of less value and need be underscored. The Table 2 shows a summary of no mediation, partial mediation and full mediation. 
Table 2: Summary of the nature of mediation

\begin{tabular}{ccccccc}
\hline Decision & Direct & & & \multicolumn{2}{c}{ Full mediation model } \\
& $\mathbf{X} \rightarrow \mathbf{Y}$ & $\mathbf{X} \rightarrow \mathbf{Y}$ & $\mathbf{S I E}$ & $\mathbf{9 5 \%} \mathbf{C I}$ \\
& $\mathbf{P}$ & Beta & $\mathbf{P}$ & $\mathbf{P}$ & $\mathbf{0}$ \\
\hline No mediation & & & & & $\mathrm{NS}$ & Inside \\
Partial mediation & $\mathrm{S}$ & $\downarrow$ & & $\mathrm{S}$ & $\mathrm{S}$ & Outside \\
Full mediation & $\mathrm{S}$ & $\downarrow$ & & $\mathrm{NS}$ & $\mathrm{S}$ & Outside \\
\hline
\end{tabular}

Using the figure 2 above, the following are the three types of mediation effects.

a. If in the relationship between W-FC (X) and JS (Y), (C) remains significant and unchanged after the inclusion of WFB (M) as an additional predictor (W-FC and WFB predict JS) then, there is no mediation effect.

b. When there is a reduction in the beta value of $\mathrm{C}$, but the latter remains significant when work family balance (M) is included as an additional predictor, then there is a partial mediation.

c. When there is a reduction in the beta value of $\mathrm{C}$, to a point where it is not statistically significant after work family balance (M) is included as an additional predictor, then there is a full mediation.

\section{CONCLUSION}

In this paper, the meaning and applications of mediation and mediation analysis respectively are enhance through the review of current literature. In addition, some of the areas of concern with respect to the pre-requirements for mediation analysis; test for relationships among the variables; number of formulated hypotheses and nature of mediation effect have been demystified alongside the increase in the knowledge base of researchers. The knowledge gained will assist scholars and practitioners make informed decisions on their research efforts with respect to analysis in the future. This study has also created the required awareness for the applications of the CB-SEM as a statistical technique for mediation analysis in the behavioural and social sciences and its relevance in the future. In addition, the study draws its importance from the need to focus on the drawbacks encountered by researchers in the adoption of the technique and the means for attending to them.

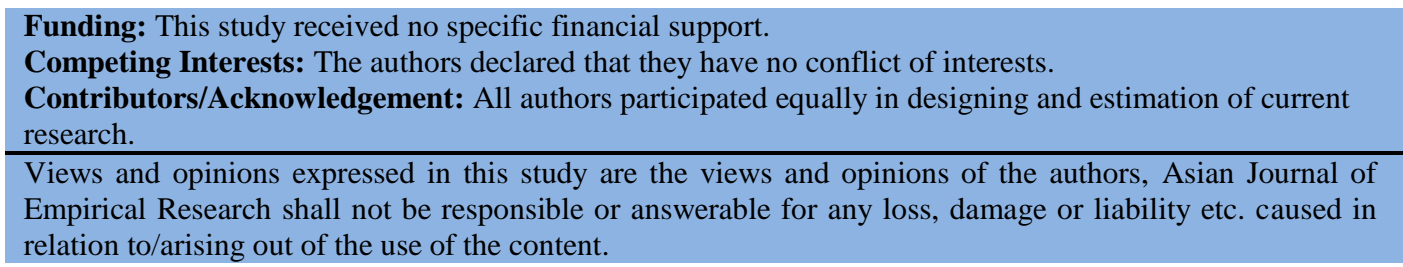

\section{References}

Aguinis, H., Alabduljader, N., Ramani, R., \& Campbell, P. (2017). How to Improve our Game: Enhancing Methodological Transparency in Management Research. In Academy of Management Proceedings (Vol. 2017, No. 1, p. 10779). Briarcliff Manor, NY 10510: Academy of Management. view at Google scholar / view at publisher

Aguinis, H., Edwards, J. R., \& Bradley, K. J. (2017). Improving our understanding of moderation and mediation in strategic management research. Organizational Research Methods, 20(4), 665685. view at Google scholar / view at publisher

Alter, A. L., \& Balcetis, E. (2011). Fondness makes the distance grow shorter: Desired locations seem closer because they seem more vivid. Journal of Experimental Social Psychology, 47(1), 1621. view at Google scholar / view at publisher 
Baron, R. M., \& Kenny, D. A. (1986). The moderator-mediator variable distinction in social psychological research: Conceptual, strategic, and statistical considerations. Journal of Personality and Social Psychology,51(6), 1173-1182. view at Google scholar / view at publisher

Brown, G., \& Baer, M. (2011). Location in negotiation: Is there a home field advantage? Organizational Behavior and Human Decision Processes, 114(2), 190-200. view at Google scholar / view at publisher

Costa, J., \& Pinto-Gouveia, J. (2011). The mediation effect of experiential avoidance between coping and psychopathology in chronic pain. Clinical Psychology \& Psychotherapy, 18(1), 34-47. view at Google scholar / view at publisher

Debeer, E., Hermans, D., \& Raes, F. (2009). Associations between components of rumination and autobiographical memory specificity as measured by a minimal instructions autobiographical memory test. Memory, 17(8), 892-903. view at Google scholar / view at publisher

Duncan, L. E., \& Stewart, A. J. (2007). Personal political salience: the role of personality in collective identity and action. Political Psychology, 28(2), 143-164. view at Google scholar / view at publisher

Fairchild, A. J., \& McQuillin, S. D. (2010). Evaluating mediation and moderation effects in school psychology: A presentation of methods and review of current practice. Journal of school psychology, 48(1), 53-84. view at Google scholar / view at publisher

Gaudiano, B. A., Herbert, J. D., \& Hayes, S. C. (2010). Is it the symptom or the relation to it? Investigating potential mediators of change in acceptance and commitment therapy for psychosis. Behavior Therapy, 41(4), 543-554. view at Google scholar / view at publisher

Goodall, C. E., \& Slater, M. D. (2010). Automatically activated attitudes as mechanisms for message effects: The case of alcohol advertisements. Communication Research, 37(5), 620-643. view at Google scholar / view at publisher

Green, D. P., Ha, S. E., \& Bullock, J. G. (2010). Enough already about "black box" experiments: Studying mediation is more difficult than most scholars suppose. The Annals of the American Academy of Political and Social Science, 628(1), 200-208. view at Google scholar / view at publisher

Green, J. P., Tonidandel, S., \& Cortina, J. M. (2016). Getting through the gate: Statistical and methodological issues raised in the reviewing process. Organizational Research Methods, 19(3), 402-432. view at Google scholar

Hair, J. F., Ringle, C. M., \& Sarstedt, M. (2011). PLS-SEM: Indeed a silver bullet. Journal of Marketing Theory and Practice, 19(2), 139-152. view at Google scholar / view at publisher

Hair, J. F., Hult, G. T. M., Ringle, C. M., \& Sarstedt, M. (2017b). A primer on partial least squares structural equation modeling (PLS-SEM), 2nd ed., Sage, Thousand Oaks, CA.

Hayes, A. F. (2009). Beyond Baron and Kenny: Statistical mediation analysis in the new millennium. Communication monographs, 76(4), 408-420. view at Google scholar / view at publisher

Hayes, A. F., \& Rockwood, N. J. (2017). Regression-based statistical mediation and moderation analysis in clinical research: Observations, recommendations, and implementation. Behaviour Research and Therapy, 98, 39-57. view at Google scholar / view at publisher

Hayes, A. F. (2013). Introduction to mediation, moderation, and conditional process analysis: a regression-based approach. New York, NY: The Guilford Press. Journal of Educational Measurement, 51(3), 335-337. view at Google scholar

Hughes, K., \& Coplan, R. J. (2010). Exploring processes linking shyness and academic achievement in childhood. School Psychology Quarterly, 25(4), 213-222. view at Google scholar / view at publisher

James, L. R., \& Brett, J. M. (1984). Mediators, moderators, and tests for mediation. Journal of Applied Psychology, 69(2), 307-321. view at Google scholar / view at publisher 
Leonard, S. A., \& Rasmussen, K. M. (2011). Larger infant size at birth reduces the negative association between maternal pregnancy body mass index and breastfeeding duration-3. The Journal of Nutrition, 141(4), 645-653. view at Google scholar / view at publisher

MacKinnon, D. P., Coxe, S., \& Baraldi, A. N. (2012). Guidelines for the investigation of mediating variables in business research. Journal of Business and Psychology, 27(1), 1-14. view at Google scholar / view at publisher

MacKinnon, D. P., Krull, J. L., \& Lockwood, C. M. (2000). Equivalence of the mediation, confounding and suppression effect. Prevention Science, 1(4), 173-181. view at Google scholar

Meade, C. S., Conn, N. A., Skalski, L. M., \& Safren, S. A. (2011). Neurocognitive impairment and medication adherence in HIV patients with and without cocaine dependence. Journal of Behavioral Medicine, 34(2), 128-138. view at Google scholar / view at publisher

Memon, M. A., Cheah, J., Ramayah, T., Ting, H., \& Chuah, F. (2018). Mediation Analysis Issues and Recommendations. Journal of Applied Structural Equation Modeling, 2(1), 1-9. view at Google scholar

Memon, M. A., Ting, H., Ramayah, T., Chuah, F., \& Cheah, J. H. (2017). A review of the methodological misconceptions and guidelines related to the application of structural equation modeling: A Malaysian scenario. Journal of Applied Structural Equation Modeling, 1(1), 1-13. view at Google scholar

Miller, T. L., del Carmen Triana, M., Reutzel, C. R., \& Trevis Certo, S. (2007). Mediation in strategic management research: Conceptual beginnings, current application, and future recommendations. In Research Methodology in Strategy and Management (pp. 295-318). Emerald Group Publishing Limited. view at Google scholar / view at publisher

Patrick, V. M., \& Hagtvedt, H. (2011). Aesthetic incongruity resolution. Journal of Marketing Research, 48(2), 393-402. view at Google scholar / view at publisher

Paulraj, A. (2011). Understanding the relationships between internal resources and capabilities, sustainable supply management and organizational sustainability. Journal of Supply Chain Management, 47(1), 19-37. view at Google scholar / view at publisher

Pieters, R. (2017). Meaningful mediation analysis: Plausible causal inference and informative communication. Journal of Consumer Research, 44(3), 692-716. view at Google scholar / view at publisher

Preacher, K. J., \& Hayes, A. F. (2004). SPSS and SAS procedures for estimating indirect effects in simple mediation models. Behavior Research Methods, Instruments, \& Computers, 36(4), 717-731. view at Google scholar / view at publisher

Preacher, K. J., \& Hayes, A. F. (2008). Asymptotic and resampling strategies for assessing and comparing indirect effects in multiple mediator models. Behavior research methods, 40(3), 879-891. view at Google scholar / view at publisher

Rahman, M. M., Abdul, M., Mansor, Z. D., Ali, N. A., Samuel, A. B., Uddin, M. J., Ogiri, I., \& Rahaman, M. S. (2018). Effect of work-family conflict on job satisfaction of academicians of private universities in Bangladesh: a structural equation modeling approach. Journal of Advanced Research in Social and Behavioral Sciences, 10(1), 1-8.

Righetti, F., \& Finkenauer, C. (2011). If you are able to control yourself, I will trust you: The role of perceived self-control in interpersonal trust. Journal of Personality and Social Psychology, 100(5), 874-886. view at Google scholar / view at publisher

Ruby, M. B., Dunn, E. W., Perrino, A., Gillis, R., \& Viel, S. (2011). The invisible benefits of exercise. Health Psychology, 30(1), 67-74. view at Google scholar / view at publisher

Rucker, D. D., Preacher, K. J., Tormala, Z. L., \& Petty, R. E. (2011). Mediation analysis in social psychology: Current practices and new recommendations. Social and Personality Psychology Compass, 5(6), 359-371. view at Google scholar / view at publisher

Rungtusanatham, M. (2001). Beyond improved quality: the motivational effects of statistical process control. Journal of Operations Management, 19(6), 653-673. view at Google scholar / view at publisher 
Rungtusanatham, M., Miller, J. W., \& Boyer, K. K. (2014). Theorizing, testing, and concluding for mediation in SCM research: Tutorial and procedural recommendations. Journal of Operations Management, 32(3), 99-113. view at Google scholar / view at publisher

Sarkis, J., Gonzalez-Torre, P., \& Adenso-Diaz, B. (2010). Stakeholder pressure and the adoption of environmental practices: The mediating effect of training. Journal of Operations Management, 28(2), 163-176. view at Google scholar / view at publisher

Schoemann, A. M., Boulton, A. J., \& Short, S. D. (2017). Determining power and sample size for simple and complex mediation models. Social Psychological and Personality Science, 8(4), 379-386. view at Google scholar / view at publisher

Shrout, P. E., \& Bolger, N. (2002). Mediation in experimental and nonexperimental studies: new procedures and recommendations. Psychological methods, 7(4), 422-455. view at Google scholar / view at publisher

Shrum, L. J., Lee, J., Burroughs, J. E., \& Rindfleisch, A. (2011). An online process model of secondorder cultivation effects: How television cultivates materialism and its consequences for life satisfaction. Human Communication Research, 37(1), 34-57. view at Google scholar / view at publisher

Wagner, J. A., Tennen, H., \& Osborn, C. Y. (2010). Lifetime depression and diabetes self-management in women with Type 2 diabetes: a case-control study. Diabetic Medicine, 27(6), 713-717. view at Google scholar / view at publisher

Wohl, M. J., \& Branscombe, N. R. (2009). Group threat, collective angst, and ingroup forgiveness for the war in Iraq. Political Psychology, 30(2), 193-217. view at Google scholar / view at publisher

Wood, R. E., Goodman, J. S., Beckmann, N., \& Cook, A. (2008). Mediation testing in management research: A review and proposals. Organizational Research Methods, 11(2), 270-295. view at Google scholar

Wu, Z., Choi, T. Y., \& Rungtusanatham, M. J. (2010). Supplier-supplier relationships in buyersupplier-supplier triads: Implications for supplier performance. Journal of Operations Management, 28(2), 115-123. view at Google scholar / view at publisher

Zhao, X., Lynch Jr, J. G., \& Chen, Q. (2010). Reconsidering baron and Kenny: myths and truths about mediation analysis. Journal of Consumer Research, 37(2), 197-206. view at Google scholar I view at publisher

Zhou, H., Benton Jr, W. C., Schilling, D. A., \& Milligan, G. W. (2011). Supply chain integration and the SCOR model. Journal of Business Logistics, 32(4), 332-344. view at Google scholar 